Proceedings

\title{
Karst Detection, Prevention and Correction: A Case Study along the Riyadh Metro Line 3 (Saudi Arabia) ${ }^{\dagger}$
}

\author{
Manuel Cueto ${ }^{1, *}$, Pablo de la Puente ${ }^{1}$, Carlos López-Fernández ${ }^{2}$, Luis Pando ${ }^{2}$ and Daniel Arias ${ }^{2}$ \\ 1 IDOM, Avda. Monasterio de El Escorial 4, 28049 Madrid, Spain; pdelapuente@idom.com \\ 2 Department of Geology, University of Oviedo, Jesús Arias de Velasco s/n, 33005 Oviedo, Spain; \\ lopezcarlos@uniovi.es (C.L.-F.); lpando@geol.uniovi.es (L.P.); darias@geol.uniovi.es (D.A.) \\ * Correspondence: mcueto@idom.com; Tel.: +34-648-747-634 \\ + Presented at the 2nd International Research Conference on Sustainable Energy, Engineering, Materials and \\ Environment (IRCSEEME), Mieres, Spain, 25-27 July 2018.
}

Published: 6 November 2018

\begin{abstract}
In the framework of the largest urban-transit system ever built from scratch, the Riyadh Metro Project (6 lines totaling $176 \mathrm{~km}$ ), a comprehensive investigation was carried out for karst detection, prevention and correction. This case study of the Metro Line $3(41.6 \mathrm{~km})$ seeks to show how the multi-technique geophysical survey (seismic refraction, electrical resistivity and ground penetration radar down to $40-50 \mathrm{~m}$ depth) was found to be a successful tool in detecting karst features. Preventive measures included systematic probing drilling to anticipate karst cavities below foundations (653 piers) and tunnel lining evaluation using 2D finite elements. Finally, this paper provides initial guidance of the corrective techniques used for each engineering challenge, such as cavity filling with grouting, geogrid reinforcement, etc.
\end{abstract}

Keywords: karst; engineering geology; Riyadh; Metro Line 3

\section{Introduction}

Most of the area of Saudi Arabia lies above soluble sedimentary rocks, with a wide variety of karst features reported in numerous areas, constituting one of the most important geohazards in the Kingdom [1,2]. Various authors have reported high potential of karst caves, sinkholes, endokarst and open fractures causing hazard for construction in Riyadh, the capital [3-6]. In particular, karst was the most significant risk faced throughout the geotechnical design assessment of the Riyadh Metro Project Line 3 (Figure 1).
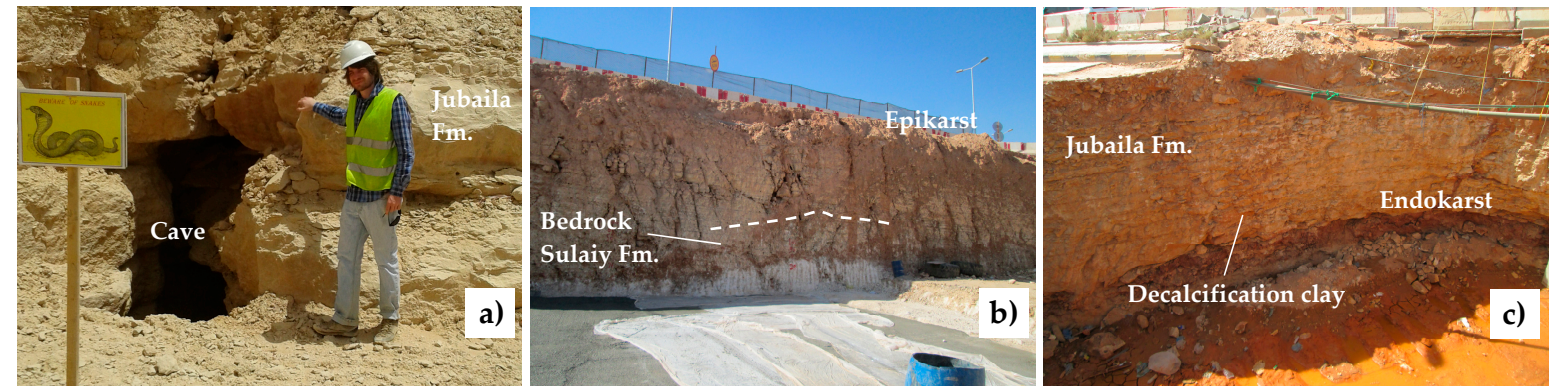

Figure 1. Different karst features found during the construction of the Riyadh Metro Line 3: (a) cave in Jubaila Fm. at the West Depot; (b) epikarst in Sulaiy Fm. at an open excavation and (c) endokarst following an interbedded dolomite layer in Jubaila Formation at the western end of Line 3 (RDAANM-IDOM). 
The Riyadh Metro is the largest urban-transit system ever built from scratch. It is a $\$ 23 \mathrm{bn}$ project with a driverless operating system, which comprises 6 lines $(176 \mathrm{~km}), 85$ stations (50 underground, 31 elevated and four at-grade), 7 depots and 25 Park \& Rides (P\&R) with expected completion by the end of 2018. Line 3 is the longest line with $41.6 \mathrm{~km}$, of which $25.7 \mathrm{~km}$ are over concrete slab viaducts, $11 \mathrm{~km}$ of underground section (including $5.7 \mathrm{~km}$ with TBM) and $4.9 \mathrm{~km}$ at grade. It includes 22 stations, 2 depots and 5 P\&R for users, with a total value of $\$ 6$ bn and 48 months of expected construction (Figure 2).

This article aims to briefly show how the multi-technique survey used for karst detection enabled us to propose mitigation procedures adapted to the karst structures. Furthermore, it lays out corrective measures which helped achieve reliable, safe and efficient designs and construction works.

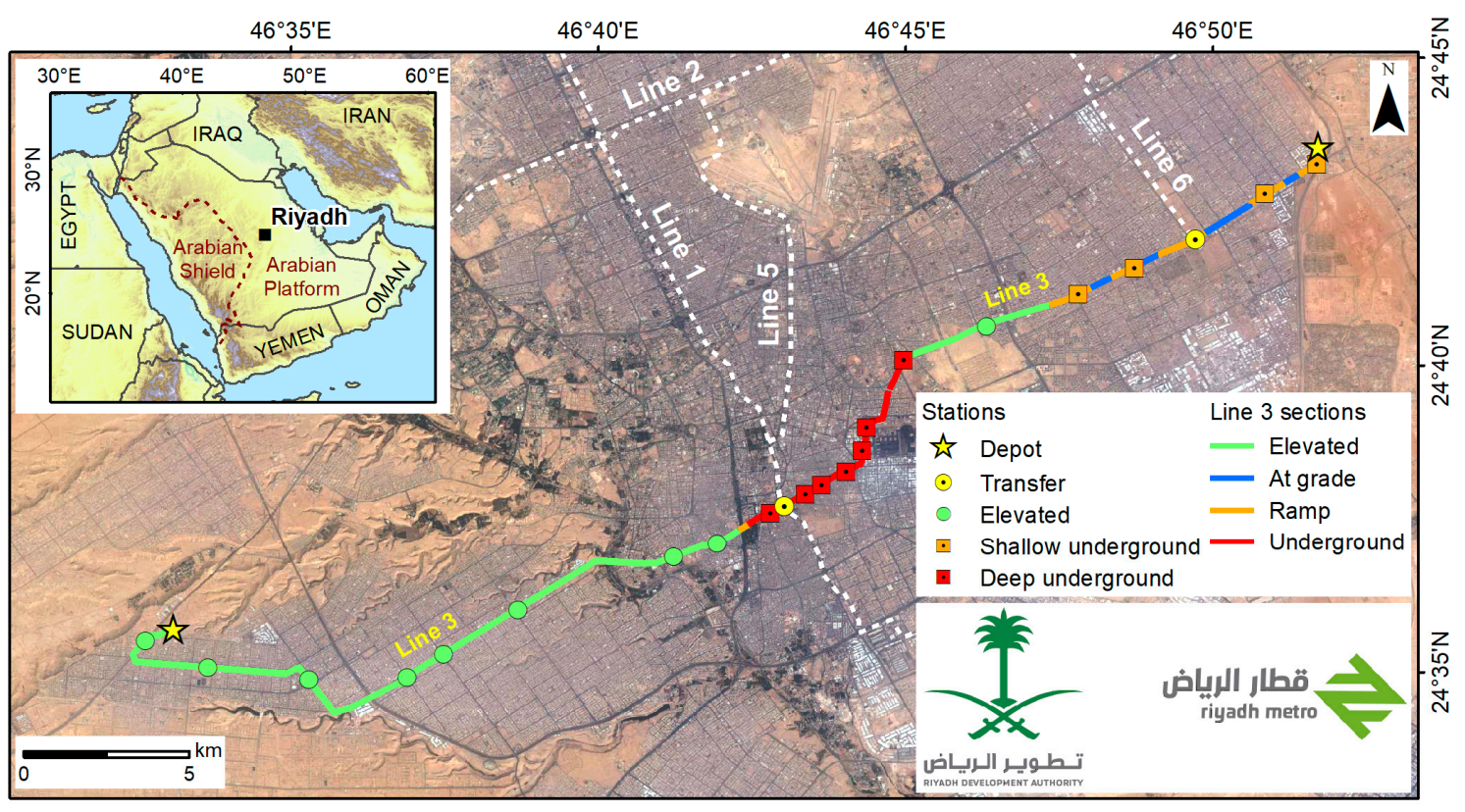

Figure 2. Riyadh Metro Project layout showing the different types of sections and stations with different colors depending on their type along the Line 3 (RDA-ANM-IDOM).

\section{Methodology}

\subsection{Detection}

An integration of multi-technique geophysical survey was carried out to detect areas with poor engineering properties related to karst features down to $40-50 \mathrm{~m}$ depth [7]. This survey included 37.8 $\mathrm{km}$ of seismic refraction tomography, conducted with an equipment of 58 geophones of $10 \mathrm{~Hz}$ spaced $10 \mathrm{~m}$ apart; $39.7 \mathrm{~km}$ of electrical resistivity tomography with an instrument of 96 channels using Wenner-Schlumberger configuration; and $39.1 \mathrm{~km}$ of ground penetration radar using a system with $100 \mathrm{MHz}$ antenna. On the basis of the results obtained via the geophysical survey, karst presence was confirmed by borehole drilling (with integral logging including measurement of core recovery, Rock Quality Designation, tv images recording, crosshole and downhole tests).

\subsection{Prevention}

As preventive measures, the ground within the footprint of shallow foundations or beneath base of socketed piles on rock (with a total of 653 viaduct pier foundations) was investigated using probing drilling in anticipation of potential karst cavities below [8]. The drilling was carried out by hydraulic rig using the rotary-percussion method and a minimum diameter of $89 \mathrm{~mm}$ to allow for later grouting. The investigation criteria for shallow foundations were based on the size of the footing with 5 to 8 probe holes at the center and corners of each location, which were extended to a depth of twice the footing width. The presence of cavities was identified following a sudden increase of drilling 
speed. For bored piles socketed in rock, probes were carried out to a depth $>3 \mathrm{~m}$ below the socket base. In addition, the tunnel lining was evaluated using 2D finite-element software modelled on a circular cavity of $1.5 \mathrm{~m}$ diameter to allow of a poor execution of the injections in the back of the ring or due to a complete loss of the injected material.

\subsection{Correction}

For karst correction, any cavities encountered at rock surface were exposed, cleaned and then filled with concrete to produce a sound footing grade. Based on the results of the preventive investigation at each foundation location, cavities were filled using grout cement. Low injection rates with limited pump-in pressures of $2-5$ bar and a water/cement ratio of 0.6 were adopted to maximize grout intake and avoid hydraulic fracturing. This treatment was considered successful when the results obtained from additional cored boreholes carried out 7 days after completion confirmed that the voids were filled. Geogrid reinforcement for pavements and embankments constructed over voids and cavities was also prescribed. Deep foundations on rock were used to circumvent large cavities at site.

\section{Results}

Following the geophysical and geotechnical investigation, the preventive programme including probing drilling showed the presence of cavities under viaduct foundations, allowing later grouting. In case of karst cavity detection, the number of probeholes was increased around the main holes in order to confirm lateral extension. Finally, cored boreholes were drilled to confirm proper grouting of cavities which also enabled laboratory tests on grouted samples to be carried out (Figure 3).
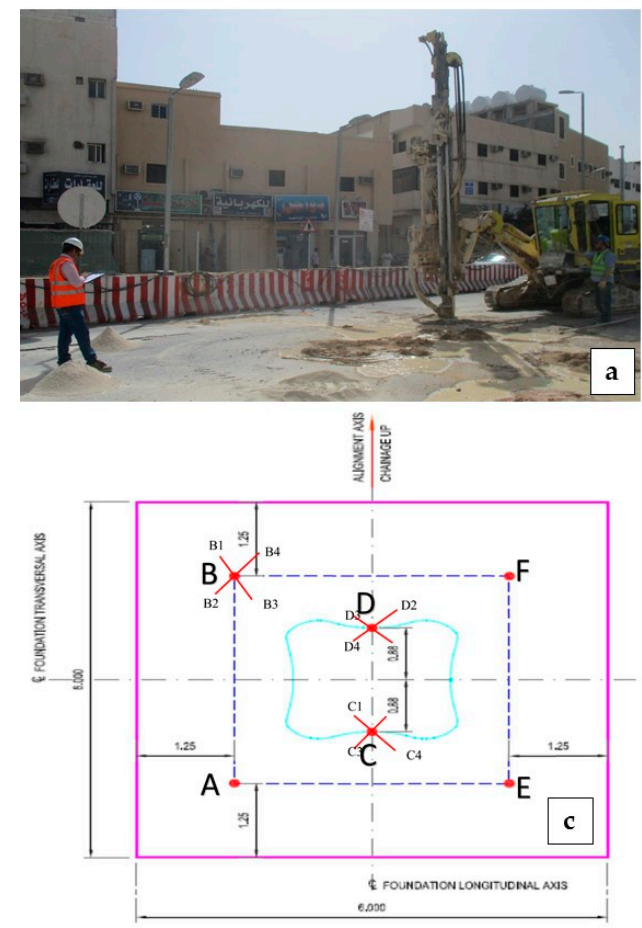
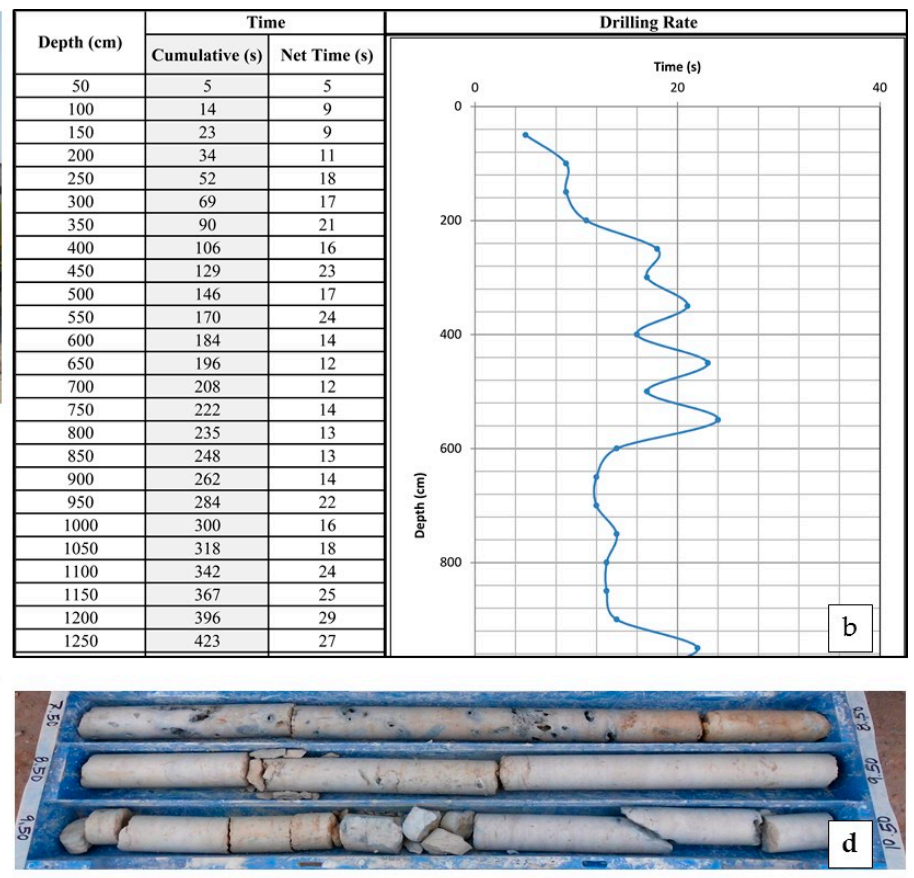

Figure 3. Probehole drilling and grouting on the footprint of a shallow foundation: (a) hydraulic rig using the rotary-percussion method; (b) probehole record with karst detection from 5.6 to $9.4 \mathrm{~m}$ depth; (c) location of 6 probeholes (A to E) on the shallow footing of $6 \times 6 \mathrm{~m}$, with red crosses marking the holes with karst where four additional probeholes were drilled to check for lateral extension of the cavity; (d) core box from confirmatory borehole to check the grouting (RDA-ANM-IDOM).

The evaluation of the cavity in various positions (intersecting the tunnel crown, the sidewall and the invert of the tunnel) confirmed the design of the tunnel lining in terms of geometry and ring reinforcement even for the most stressed section (Figure 4). Long term necessity requires that these cavities must be grouted in order to ensure segmental lining behavior. 


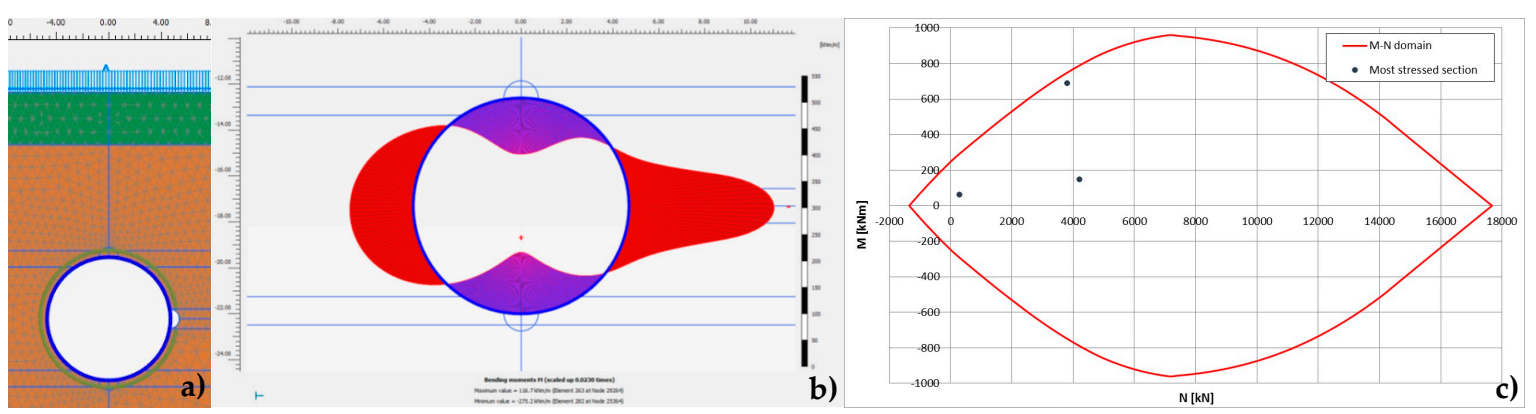

Figure 4. Tunnel Lining evaluation: (a) Plaxis 2D model; (b,c) structural verification of ring with cavity $1.5 \mathrm{~m}$ in terms of bedding moment and axial force (RDA-ANM-IDOM-ROCKSOIL).

\section{Conclusions}

The geotechnical investigation, prevention and correction methodology carried out along the Riyadh Metro Line 3 was found to be a time and cost-effective tool to minimize the risk involved in construction in karstic terrain. However, this risk cannot be fully addressed and specific measures should be taken when designing infrastructure construction projects in karstic areas. Given the possibility of small karstic cavities (which could remain undetected even after probeholes and geophysical surveys), lower values of bearing capacity should be considered in order to redistribute stresses evenly around cavities. In addition, the bottom of excavations in rock should be thoroughly inspected by an experienced geologist or geotechnical engineer and any weathered material removed before casting. This case study provides initial guidance on techniques to be used in similar contexts.

Acknowledgments: We thank IDOM Consulting, Engineering, Architecture, S.A.U. for supporting this research and especially all the staff involved in the design of the Line 3. Also, the authors gratefully acknowledge Saudi Arabia's Riyadh Development Authority (RDA) promoting the Riyadh Metro Project and especially ArRiyadh New Mobility Consortium (ANM) selected to deliver the Package 2-Line 3.

Funding: This research received no external funding.

\section{References}

1. Al-Refeai, T.; Al-Ghamdy, D. Geological and geotechnical aspects of Saudi Arabia. Geotech. Geol. Eng. 1994, 12, 253-276.

2. Amin, A.A.; Bankher, K.A. Karst Hazard Assessment of Eastern Saudi Arabia. Nat. Hazards 1997, 15, 21-30.

3. Youssef, A.M.; Al-Harbi, H.M.; Gutiérrez, F.; Zabramwi, Y.A.; Bulkhi, A.B.; Zahrani, S.A.; Bahamil, A.M.; Zahrani, A.J.; Otaibi, Z.A.; El-Haddad, B.A. Natural and human-induced sinkhole hazards in Saudi Arabia: Distribution: Distribution, investigation, causes and impacts. Hydrogeol. J. 2016, 24, 625-644.

4. Abd El-Aal, A. Identification and characterization of near surface cavities in Tuwaiq Mountain Limestone, Riyadh, KSA, “detection and treatment". Egypt. J. Pet. 2017, 26, 215-223.

5. Abd El-Aal, A.K. Geomechanical Aspects and Suitability of the Limestone (Sulaiy Limestone Formation) for Foundation Bedrock, Sulaiy Region, Saudi Arabia. J. Geol. Geophys. 2015, 4, 1-5.

6. Abdeltawab, S. Karst Limestone Geohazards in Egypt and Saudi Arabia. Int. J. Geoeng. Case Hist. 2013, 2, 258-269.

7. Cueto, M.; Olona, J.; Fernández-Viejo, G.; Pando, L.; López-Fernández, C. Karst-induced sinkhole detection using an integrated geophysical survey: A case study along the Riyadh Metro Line 3 (Saudi Arabia). Near Surf. Geophys. 2018, 16, 270-281.

8. Ahmad, S.F. Managing Sinkholes at Project Site, A Saudi Arabian Case History. In Proceedings of the Fifth International Conference on Case Histories in Geotechnical Engineering, New York, NY, USA, 13-17 April 2004; pp. 1-9.

(C) 2018 by the authors. Licensee MDPI, Basel, Switzerland. This article is an open access article distributed under the terms and conditions of the Creative Commons Attribution (CC BY) license (http://creativecommons.org/licenses/by/4.0/). 